\title{
PSYCHOLOGICAL DETACHMENT AS MODERATOR BETWEEN PSYCHOSOCIAL WORK CONDITIONS AND LOW BACK PAIN DEVELOPMENT
}

\author{
TOBIAS MIERSWA ${ }^{1}$ and MICHAEL KELLMANN ${ }^{1,2}$ \\ ${ }^{1}$ Ruhr University Bochum, Bochum, Germany \\ Faculty of Sport Science, Unit of Sport Psychology \\ ${ }^{2}$ The University of Queensland, St Lucia, Australia \\ School of Psychology
}

\begin{abstract}
Objectives: Recovery processes in leisure time influence the effect of psychosocial work factors on health issues. However, this function of recovery has been neglected in research regarding the influence of work-related risk factors on low back pain (LBP) development. The aim of this prospective study was to examine the function of psychological detachment a relevant recovery experience - concerning the influence of psychosocial work factors on LBP development. A moderating function of detachment for the interplay of work factors and LBP was assumed. Material and Methods: Sixty pain-free administrative employees of German universities completed an online survey 3 times during a 6-month period. Generalized estimating equations were used to estimate risk-factors of LBP. Results: Analyses revealed an increased chance of LBP development for smokers and a decreasing chance when work resources were high. Detachment had no direct influence on LBP development, although it moderated the influence of work stressors and work resources on LBP. On the one hand, high detachment values seem to protect against an increased chance of LBP development when employees were confronted with high work stressors, while on the other hand high detachment values enhance the protective effect of high work resources. Conclusions: The results indicated a moderating role of detachment concerning the influence of psychosocial work factors on LBP development. Therefore, it is necessary to include recovery processes in future research regarding LBP development and consequently in LBP prevention concepts. Int J Occup Med Environ Health 2017;30(2):313-327
\end{abstract}

Key words:

Risk factors, Low back pain, Leisure time, Detachment, Work resources, Work stressors

\section{INTRODUCTION}

Low back pain (LBP) is a common health problem worldwide, causing high economic and societal costs [1-3], as well as high individual social and psychological burden for affected persons [4-6]. In Hoy et al.'s [7] systematic review, the 1-year prevalence of LBP amounted to 83\%, while Thiese et al. [8] more recently reported a LBP-lifetime prevalence ranging 58-85\%. Scientists have therefore tried to identify relevant risk factors associated with LBP development to improve prevention and reduce the socio-economic costs caused by LBP.

Funding: the theoretical deliberations of this article have been compiled within the framework of the project "Backpain" ("Rückenschmerz") (IIA1-080102B/11-14), initiated and funded by the German Federal Institute of Sport Science and realized within MiSpEx - the National Research Network for Medicine in Spine Exercise. Received: November 26, 2015. Accepted: April 12, 2016.

Corresponding author: T. Mierswa, Ruhr University Bochum, Faculty of Sport Science, Unit of Sport Psychology, Gesundheitscampus Nord 10, 44801 Bochum, Germany (e-mail: tobias.mierswa@rub.de). 


\section{Risk factors of LBP development}

In the last 20 years, research has emphasized the importance of work-related psychosocial factors and possible interactions of psychosocial and physical demands at work [9-13]. According to these studies, LBP risk increases by both high straining psychosocial work factors (stressors) such as monotone work processes or high work demands, as well as low supportive psychosocial work factors (resources) such as social support, work control, and job satisfaction $[14,15]$. Furthermore, straining leisure time activities such as housework or caring for family members or unsatisfying leisure time enhance the risk of LBP development [10,16,17].

While the exact mechanisms by which these risk factors cause LBP remain unclear, strain and associated load reactions have been shown to be related to LBP occurrence [18-21]. Strain is thought to be caused by the interplay of the work stressors and work resources, as described in the Job Demands-Resources Model (JD-R Model) [22,23]. According to this model, the confrontation with strong work stressors leads to strain perceptions and the occurrence of health complaints. Work resources could buffer the influence of work stressors on strain and thereby reduce the risk of health complaints. Similarly, general work-health models emphasize the importance of stress at work and associated physical and psychological load reactions for developing health problems, including back pain $[24,25]$.

\section{Recovery and work strain}

According to Geurts and Sonnentag [26] and Kallus [27], recovery could contradict the unhealthy influence of work strain and adequate recovery is important for employees to keep healthy. More specifically, Mierswa and Kellmann [28] described 2 distinct functions of recovery with respect to the influence of work strain on LBP development. On the one hand, recovery lessened the strength of acute load reactions, given that a person is more capable of coping with work strains if they are well recovered. On the other hand, recovery processes can stop an ongoing psychological confrontation with work strains, also known as rumination $[29,30]$. Consequently, recovery can prevent an accumulation of stress and reduce the risk of health issues. Empirical studies support these theoretical considerations, suggesting that adequate recovery processes in leisure time lead to a more positive affective state, an increase in well-being, and a reduction in perceived work strain and need of recovery [31-37].

An essential recovery process is detachment, defined by Geurts and Sonnentag [26] as a basic recovery process not linked to a specific behavior but rather as a process of physically and psychologically distancing from work strains during leisure time. In this function, detachment is necessary to stop thinking about the work strain and prevent ruminating thoughts. Only if a person is able to stop ruminating on work strains they can recover adequately in leisure time because rumination leads to maintenance of stress reactions [33,38-40].

\section{Recovery and health complaints}

Several studies indicated a promoting influence of recovery on well-being and on health in general [41-45], as well as on specific health complaints such as cardiovascular diseases $[46,47]$ or muscle-skeletal diseases [48-50]. Participants with low recovery states showed a higher risk of health complaints and were at twice the risk of missing work due to sickness absence [51]. In addition, few studies indicated an interaction effect of detachment and work factors on psychosomatic health complaints. According to Sonnentag et al. [38], high work demands only led to an increase in health complaints when the participants had low detachment values. Similarly, Mierswa and Kellmann [52] identified a direct positive association between detachment and LBP, as well as interaction effects of detachment with the scales Work stressors and Organizational climate. Detachment values were negatively 
associated with LBP and only persons with a low ability to detach showed LBP more often when they perceived either high stressors or a good working climate. Detachment thus moderated the association of work factors with LBP in this cross-sectional study.

\section{Aim of the study}

The indicated influences of recovery processes - and especially detachment - on LBP development have not been investigated in a longitudinal study to date. Studies in the field of psychosocial LBP risk factors have mostly neglected the influence of recovery processes, even though the interplay of recovery processes and work factors has long been known. Therefore, the main aim of this study was to investigate the influence of detachment on LBP development and its interaction with psychosocial work factors. In line with these results of previous studies the following 3 hypothesis $(\mathrm{H})$ are tested:

- H1: employees with high detachment values have lesser odds of developing LBP in the following 6 months,

- H2: detachment interacts with work stressors, such that employees with low detachment values show a higher increase in LBP risk when work stressors increase compared to those with high detachment values,

- H3: detachment interacts with work resources, such that employees with high detachment values have a lower LBP risk when work resources reduce compared to those with low detachment values.

\section{MATERIAL AND METHODS}

\section{Sample}

The study population comprised a subsample of pain-free participants from a larger sample of administration employees from 13 universities in North Rhine-Westphalia, Germany [52]. Administrative employees were defined as employees working in central university administrations, as well as department secretariats or libraries. The job of the study population is characterized by computer work and sitting. The staff council of each university contacted the administrative employees via an email, containing initial study information and a link to the online survey.

Criteria for inclusion in the analysis were the absence of LBP at baseline (T1), over 19 working h/week and a minimum age of 18 years. Overall, 821 employees completed the online survey at baseline, 271 of whom (32\%) reported no LBP at baseline (T1). A comparison of the pain-free participants with those suffering from LBP can be found in Mierswa and Kellmann [52].

Two follow-up measurements (T2, T3) were conducted at intervals of 3 months. For the follow-up measurements, the staff council of their university contacted the same employees again via email. Overall, 60 participants (22\%) with no LBP at T1 completed the online survey at all 3 time points: these 60 participants form the sample for the present study.

\section{Measurements}

The online program SoSci Survey was used to design the online survey. Informed consent clause was included on the first page and participants had to give their assent to participate in the study by clicking on a button. On the next page, participants had to create a 5-digit code to enable pseudonymisation of the data. Subsequently, they received the questions as described below.

First, participants had to indicate their age in years, their gender, had to answer whether they smoke ("yes" or "no;" smoking) and participants had to indicate their weekly working hours in the last 3 months including overtime (working hours), as well as the average hours of overtime per week in the last 3 months (overtime).

A dichotomous item of the Nordic Musculoskeletal Questionnaire [53] was used to assess the existence of LBP. Participants had to indicate whether they had trouble (such as ache, pain, discomfort, numbness) in the lower back in the last 3 months by marking "yes" or "no." As in previous studies [54-56], the time span of the question was reduced 
from 12 months to 3 months, corresponding to follow-up measurements sequence.

In addition, the German version of the Chronic Pain Grade Scale (CGPS) was used to examine pain intensity and disability caused by LBP [57]. Participants had to indicate their acute pain intensity, as well as the average and highest pain intensity in the previous 3 months on an 11-point Likert scale, ranging from 0 ("no pain") to 10 ("pain as bad as it could be"). Disability was rated by indicating how strongly LBP has changed workability, social and family activities and everyday activities in the previous 3 months, based upon a scale ranging from 0 ("no interference") up to 10 ("total interference"). Finally, participants were asked to indicate the numbers of days that LBP prevented them from carrying out their everyday activities. Overall pain intensity ( $\alpha=0.93)$, overall disability $(\alpha=0.74)$ and chronification grade were computed using descriptions by von Korff et al. [58].

The Kurzfragebogen zur Arbeitsanalyse (KFZA - Short Questionnaire for Work Analysis) developed by Prümper et al. [59] had to be subsequently completed to indicate the psychosocial work factors. The KFZA comprises 26 statements concerning work experiences and organizational aspects. Participants had to rate the extent to which they agree with those statements on a 5-point Likert scale, ranging from 1 ("fully disagree") to 5 ("fully agree"). The items can be summarized to 4 scales containing 2-4 subscales: work resources (social support, teamwork, and autonomy), work stressors (qualitative demands, quantitative demands, interruptions, and environmental stress), organizational climate (involvement and career opportunities), and work content (versatility and holism). In the present study, Cronbach's $\alpha$ for the 4 scales ranged from 0.65 for work stressors to 0.81 for work content.

The detachment scale of the Recovery Experience Questionnaire [60] was included in the online survey to ascertain participants' ability to detach from work in leisure time. For 4 items (e.g., "I forget about work"), participants had to indicate how strongly they agree with statements regarding experiences in leisure time on a 5-point Likert scale, ranging from 1 ("fully disagree") to 5 ("fully agree") again. The scale had a high reliability, with a Cronbach's $\alpha$ of 0.89 .

Low back pain baseline and follow-up surveys were identical, apart from the questions regarding the socio-demographic factors of gender, age, and smoking behavior, which were included only in the baseline survey.

\section{Statistics}

The data was analyzed with the computer program Statistical Package for Social Sciences (SPSS), version 22. First, group comparisons were conducted to identify possible differences between the chosen study sample and those participants who did not take part in all 3 measurements. Independent t-tests were used for all metric variables and $\mathrm{Chi}^{2}$ test for the dichotomous (gender and smoking) variables.

A descriptive analysis of the socio-demographic factors was conducted and correlations between all measurements were analyzed. Subsequently, the sample was divided into employees who reported no LBP in the period of investigation (healthy group - HG) and those who developed LBP (pain group - PG). Cross-sectional group differences between HP and PG at T1 were analyzed with $\mathrm{Chi}^{2}$ tests for gender and smoking. Mann-Whitney $U$ tests was used for analyzing group differences in age, working hours, overtime, psychosocial work factors, and detachment.

To examine the influence of socio-demographic factors, working time, overtime, psychosocial work factors, and detachment on LBP development, generalized estimating equations (GEE) model for repeated measurements was carried out. Generalized estimating equations is an extension of the generalized linear model taking into account within-subject correlations of the dependent variables under examination. A detailed description of 
the GEE analysis can be found in Ballinger [61]. Subsequently, 3 models were constructed to integrate the predictors step-wise, whereby the existence of LBP was used as a binominal outcome variable. The first model (Model 1) included socio-demographic (gender, age, smoking) and work-related factors (working hours, overtime, KFZA subscales). The detachment scale was included in the second model (Model 2) to test for a main effect of detachment on LBP development. In the last model (Model 3), the interactions of detachment with the KFZA subscales were integrated to check for possible interaction effects.

Aside from the 2 dichotomous predictors (gender and smoking), all other predictors were continuous and Z-standardized to make the results more comprehensible. The values of the work-related factors and detachment from all 3 measurement points were included in the GEE. As described by Pan [62], the Quasi-likelihood under the Independence model Criterion (QIC) was used to determine the best fitting working correlation matrix and the Corrected Quasi-likelihood under the Independence model Criterion (QICC) as a goodness of fit parameter for the used models. Based upon the QIC values, an independent working correlation matrix was chosen for the final GEE analyses.

\section{RESULTS}

The groups comparisons revealed no significant differences between the study sample and excluded participants for all relevant predictors at T0. The mean age of the study sample was 42.53 years (standard deviation $(\mathrm{SD})=11.29$ ), ranging $21-60$ years, and $80 \%$ of them were women. During the previous 3 months participants worked $38 \mathrm{~h} /$ week $(\mathrm{SD}=8.55$, minimum $=20 \mathrm{~h} /$ week, maximum $=60 \mathrm{~h} /$ week $)$. Most of the participants $(70 \%)$ identified their type of employment as full-time job (> $35 \mathrm{~h} /$ week). Over $1 / 2$ of the sample $(53 \%)$ reported at least $1 \mathrm{~h}$ of overtime per week: the mean score was $2.13 \mathrm{~h}$ $(\mathrm{SD}=3.62)$, with a maximum of $20 \mathrm{~h}$.

The correlations between all predictor variables are presented in Table 1. The correlation analysis revealed strong relations between the KFZA subscales work content, work resources, and organizational climate, with correlation coefficients (r) ranging 0.53-0.72. Consequently, those subscales were merged together to a general work resources

Table 1. Correlations of predictor variables at baseline measurement of influence of work-related risk factors and detachment on low back pain (LBP) development in administrative employees $(\mathrm{N}=60)$ of German universities

\begin{tabular}{|c|c|c|c|c|c|c|c|c|c|}
\hline \multirow{2}{*}{ Variable } & \multicolumn{9}{|c|}{ Correlations } \\
\hline & 1 & 2 & 3 & 4 & 5 & 6 & 7 & 8 & 9 \\
\hline 1. Gender & - & & & & & & & & \\
\hline 2. Age & 0.16 & - & & & & & & & \\
\hline 3. Smoking & $-0.32 *$ & $0.26^{*}$ & - & & & & & & \\
\hline 4. Working hours & -0.07 & -0.21 & 0.02 & - & & & & & \\
\hline 5. Overtime & -0.09 & -0.07 & 0.05 & $0.66^{* * *}$ & - & & & & \\
\hline 6. Work stressors & -0.07 & -0.18 & -0.04 & $0.49 * * *$ & $0.49 * * *$ & - & & & \\
\hline 7. Work resources & -0.08 & 0.08 & 0.06 & -0.04 & -0.11 & -0.19 & - & & \\
\hline 8. Organizational climate & 0.01 & 0.01 & -0.03 & -0.05 & -0.09 & -0.21 & $0.63^{* * *}$ & - & \\
\hline 9. Work content & -0.16 & 0.08 & 0.10 & 0.02 & 0.01 & -0.19 & $0.72 * * *$ & $0.45^{* * *}$ & - \\
\hline 10. Detachment & -0.13 & 0.12 & -0.04 & -0.22 & -0.17 & $-0.34 * *$ & $0.34^{* *}$ & 0.25 & $0.39 * *$ \\
\hline
\end{tabular}

${ }^{*} \mathrm{p}<0.05 ; * * \mathrm{p}<0.01 ; * * \mathrm{p}<0.001$. 
factor by calculating the mean of the 3 subscales. The factor was labeled overall work resources and was integrated as a predictor into the GEE models, rather than the 3 individual KFZA subscales.

During the study period of 6 months, 23 participants $(38 \%)$ reported a new phase of LBP. Those 23 participants formed the $\mathrm{PG}$, whereas the remaining pain-free participants formed the HG. Overall, 11 employees (18\%) reported LBP after 3 months and 20 employees (33\%) after 6 months. Of those participants who reported LBP after 3 months, 8 (73\%) also reported LBP at 6-month follow-up. Pain parameters of the PG for both follow-up measurements are presented in Table 2.

Values of the socio-demographic data, psychosocial work factors, and detachment and group differences between HG and PG are listed in Table 3. There was a significant difference between both groups in terms of smoking $\left(\mathrm{Chi}^{2}=8.46\right.$, degree of freedom $(\mathrm{df})=1, \mathrm{p}<0.01$, Cramer's $V=0.38$ ), indicating that participants of the $P G$ smoked more regularly. Apart from smoking, group comparison showed no further significant differences between PG and HG at the baseline measurement.

The results of the 3 analyzed GEE models are presented in Table 4. The factors smoking and overall work resources were significant predictors of LBP development in all 3 models. Integrating detachment into the analysis (Model 2) reduced the goodness of fit values and no significant main effect of detachment occurred. Adding the interaction terms of detachment with the psychosocial work factors in Model 3 led to a better goodness of fit compared to Models 1 and 2. Furthermore, both interaction terms reached a significant level.

The odds ratios (OR) of the final model (Model 3) are presented in Table 5. The chance of developing LBP for participants who did not smoke was 0.24 as high as for smoking participants. Whereas work stressors had no main effect on LBP development, the chance of LBP development reduced when the overall work resources increased. The significant interaction effects between detachment and the psychosocial work factors are displayed in Figures 1 and 2 for visualization.

As shown in Figure 1, detachment moderated the influence of work stressors on the predicted LBP probability. Those participants with high detachment values showed almost no higher LBP risk when the work stressors increased. However, those with low detachment values showed a strong increase in LBP values when the work stressors rose.

As visualized in Figure 2, participants with high detachment values had a similar risk of LBP development compared to

Table 2. Pain parameters of administrative employees of German universities - study participants with low back pain (LBP) for 3- and 6-month follow-up measurements

\begin{tabular}{lcc}
\hline \multirow{2}{*}{\multicolumn{1}{c}{ Variable }} & \multicolumn{2}{c}{$\begin{array}{c}\text { Respondents } \\
(\mathrm{N}=60)\end{array}$} \\
\cline { 2 - 3 } & $\begin{array}{c}\text { 3-month follow-up } \\
(\mathrm{N}=11,18.3 \%)\end{array}$ & 6-month follow-up \\
& $\mathrm{N}=20,33.3 \%)$ \\
\hline Overall pain intensity $(\mathrm{M} \pm \mathrm{SD})$ & $31.21 \pm 16.55$ & $27.17 \pm 13.43$ \\
Overall disability $(\mathrm{M} \pm \mathrm{SD})$ & $14.24 \pm 16.24$ & $10.00 \pm 10.71$ \\
Chronification grade $[\mathrm{n}(\%)]$ & & \\
1 & $9(15.0)$ & $18(30.0)$ \\
2 & $2(3.3)$ & $2(3.3)$ \\
3 & $0(0.0)$ & $0(0.0)$ \\
4 & $0(0.0)$ & $0(0.0)$ \\
\hline
\end{tabular}

M - mean; SD - standard deviation. 
Table 3. Baseline characteristics and comparison of healthy group and low back pain (LBP) group in administrative employees of German universities

\begin{tabular}{|c|c|c|c|c|}
\hline \multirow[b]{2}{*}{ Variable } & \multicolumn{3}{|c|}{ Respondents } & \multirow[b]{2}{*}{ Group comparison } \\
\hline & $\begin{array}{c}\text { total } \\
(\mathrm{N}=60)\end{array}$ & $\begin{array}{l}\text { healthy group } \\
\quad(\mathrm{N}=37)\end{array}$ & $\begin{array}{l}\text { LBP group } \\
(\mathrm{N}=23)\end{array}$ & \\
\hline 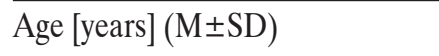 & $42.53 \pm 11.29$ & $42.57 \pm 11.77$ & $42.48 \pm 10.73$ & $\mathrm{U}=424.00, \mathrm{Z}=-0.02, \mathrm{p}>0.05$ \\
\hline Gender $[\mathrm{n}(\%)]$ & & & & $\mathrm{Chi}^{2}=0.07, \mathrm{~V}=0.03, \mathrm{p}>0.05$ \\
\hline males & $12(20.0)$ & $7(18.9)$ & $5(21.7)$ & \\
\hline females & $84(80.0)$ & $30(81.1)$ & $18(78.3)$ & \\
\hline Smoking [n (\%)] & & & & $\mathrm{Chi}^{2}=8.46, \mathrm{~V}=0.38, \mathrm{p}<0.01$ \\
\hline no & $46(76.7)$ & $33(89.2)$ & $13(56.5)$ & \\
\hline yes & $14(23.3)$ & $4(10.8)$ & $10(43.5)$ & \\
\hline Working time $[\mathrm{h}](\mathrm{M} \pm \mathrm{SD})$ & $38.00 \pm 8.55$ & $37.59 \pm 8.81$ & $38.65 \pm 8.25$ & $\mathrm{U}=409.50, \mathrm{Z}=-0.25, \mathrm{p}>0.05$ \\
\hline Overtime $(\mathrm{M} \pm \mathrm{SD})$ & $2.13 \pm 3.62$ & $1.97 \pm 3.62$ & $2.39 \pm 3.68$ & $U=414.50, Z=-0.18, p>0.05$ \\
\hline Work stressors $(\mathrm{M} \pm \mathrm{SD})$ & $2.50 \pm 0.66$ & $2.48 \pm 0.66$ & $2.54 \pm 0.67$ & $\mathrm{U}=411.00, \mathrm{Z}=-0.22, \mathrm{p}>0.05$ \\
\hline Work resources $(\mathrm{M} \pm \mathrm{SD})$ & $3.64 \pm 0.71$ & $3.57 \pm 0.57$ & $3.25 \pm 0.80$ & $\mathrm{U}=316.00, \mathrm{Z}=-1.67, \mathrm{p}>0.05$ \\
\hline Organizational climate $(\mathrm{M} \pm \mathrm{SD})$ & $2.96 \pm 0.84$ & $3.05 \pm 0.82$ & $2.80 \pm 0.86$ & $U=357.50, Z=-1.04, p>0.05$ \\
\hline Work content $(\mathrm{M} \pm \mathrm{SD})$ & $3.74 \pm 0.81$ & $3.87 \pm 0.62$ & $3.52 \pm 1.01$ & $\mathrm{U}=367.00, \mathrm{Z}=-0.89, \mathrm{p}>0.05$ \\
\hline Detachment $(\mathrm{M} \pm \mathrm{SD})$ & $3.31 \pm 0.96$ & $3.47 \pm 0.87$ & $3.07 \pm 1.06$ & $\mathrm{U}=339.00, \mathrm{Z}=-1.32, \mathrm{p}>0.05$ \\
\hline
\end{tabular}

M - mean; SD - standard deviation; U - U-value; Z - standardized Z-value; V - Cramer's V.

Table 4. Generalized estimating equations (GEE) models showing the influence of the predictors on low back pain (LBP) development in administrative employees $(\mathrm{N}=60)$ of German universities

\begin{tabular}{lcccccc}
\hline \multirow{2}{*}{ Predictor } & \multicolumn{2}{c}{ Model 1 } & \multicolumn{2}{c}{ Model 2 } & \multicolumn{2}{c}{ Model 3 } \\
\cline { 2 - 6 } & $\mathrm{B}$ & $\mathrm{SE}$ & $\mathrm{B}$ & $\mathrm{SE}$ & $\mathrm{B}$ & $\mathrm{SE}$ \\
\hline Constant & -0.72 & $0.30^{*}$ & -0.69 & $0.32^{*}$ & -0.69 & 0.36 \\
Gender (male) & -0.46 & 0.56 & -0.49 & 0.58 & -0.38 & 0.60 \\
Age & -0.23 & 0.29 & -0.23 & 0.29 & -0.26 & 0.30 \\
Smoking (no) & -1.23 & $0.44^{* *}$ & -1.27 & $0.46^{* *}$ & -1.44 & $0.52^{* *}$ \\
Working time & -0.15 & 0.26 & -0.13 & 0.26 & -0.14 & 0.27 \\
Overtime & 0.02 & 0.28 & 0.03 & 0.29 & -0.09 & 0.26 \\
Work stressors & 0.17 & 0.23 & 0.21 & 0.26 & 0.15 & 0.28 \\
Overall work resources & -0.57 & $0.25^{*}$ & -0.61 & $0.26^{*}$ & -0.75 & $0.31^{* *}$ \\
Detachment & & & 0.15 & 0.25 & 0.06 & 0.26 \\
Work stressors $\times$ detachment & & & & & -0.43 & $0.21^{*}$ \\
Overall work resource $\times$ detachment & & & & & -0.67 & $0.22^{* *}$ \\
QIC & 164.49 & & 166.78 & & 162.41 & \\
QICC & 165.76 & & 167.38 & & 164.58 & \\
\hline
\end{tabular}

Model 1 - socio-demographic (gender, age, smoking) and work-related factors (working hours, overtime, KFZA subscales).

Model 2 - detachment scale to test for a main effect of detachment on LBP development.

Model 3 - interaction terms of detachment with the KFZA (The Kurzfragebogen zur Arbeitsanalyse - Short Questionnaire for Work Analysis) subscales to check for possible interaction effects.

B - unstandardized regression coefficient; SE - standard error.

QIC - Quasi-likelihood under the Independence model Criterion; QICC - Corrected Quasi-likelihood under the Independence model Criterion. $* \mathrm{p}<0.05 ; * \mathrm{p}<0.01$. 
Table 5. Odds ratios for the predictors of Model $3^{\mathrm{a}}$ in study of administrative employees $(\mathrm{N}=60)$ of German universities

\begin{tabular}{|c|c|c|}
\hline Predictor & OR & $95 \% \mathrm{CI}$ \\
\hline Constant & 0.50 & $0.25-1.02$ \\
\hline Gender (male) & 0.68 & $0.21-2.21$ \\
\hline Smoking (no) & $0.24 * *$ & $0.09-0.65$ \\
\hline Age & 0.77 & $0.43-1.39$ \\
\hline Working time & 0.87 & $0.51-1.48$ \\
\hline Overtime & 0.92 & $0.55-1.54$ \\
\hline Work stressors & 1.17 & $0.68-2.01$ \\
\hline Overall work resources & $0.47^{* *}$ & $0.26-0.86$ \\
\hline Detachment & 1.06 & $0.63-1.78$ \\
\hline Work stressors $\times$ detachment & $0.65^{*}$ & $0.43-0.99$ \\
\hline Overall work resources $\times$ detachment & $0.51^{* *}$ & $0.33-0.79$ \\
\hline
\end{tabular}

${ }^{a}$ Integrated interactions of detachment with the KFZA (The Kurzfragebogen zur Arbeitsanalyse - Short Questionnaire for Work Analysis) subscales to check for possible interaction effects.

OR - odds ratio; $\mathrm{CI}$ - confidence interval.

$* \mathrm{p}<0.05 ; * \mathrm{p}<0.01$.

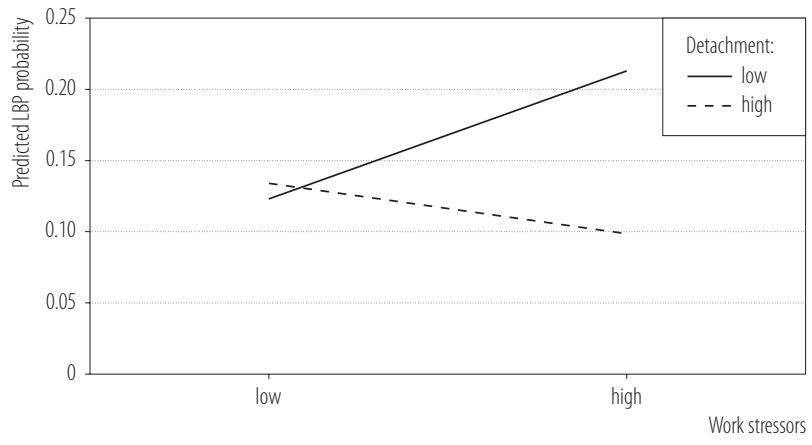

Low and high groups were formed by use of median split for the respective variable.

Fig. 1. Interaction effect of work stressors and detachment on the predicted low back pain (LBP) probability in study of administrative employees $(\mathrm{N}=60)$ of German universities

those with low detachment values when overall work resources were low. However, participants with high detachment values showed a stronger reduction of LBP risk.

Taken together, the analyses revealed an increasing influence of smoking and low overall work resources on LBP development during a 6-month period. Whereas detachment had no main effect on LBP development, it

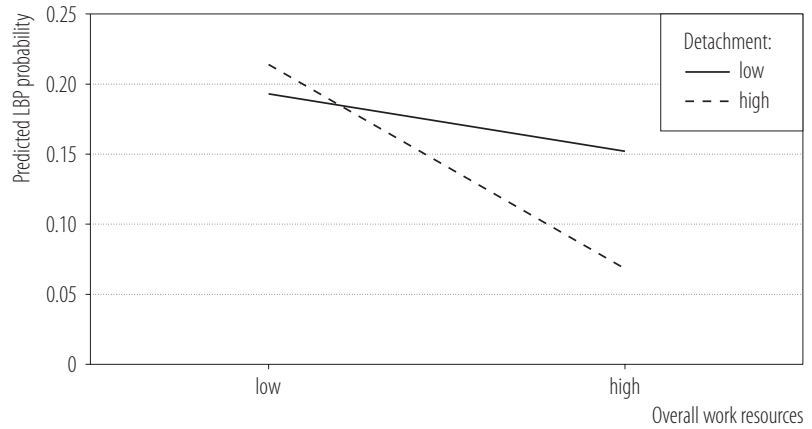

Low and high groups were formed by use of median split for the respective variable.

Fig. 2. Interaction effect of overall work resources and detachment on the predicted low back pain (LBP) probability in study of administrative employees $(\mathrm{N}=60)$ of German universities

moderated the influence of work stressors and overall work resources on the predicted LBP probability.

\section{DISCUSSION}

Several psychosocial work factors have been shown to increase the risk of LBP development in previous studies. Strain-inducing factors such as monotonous work or 
high work demands increase the LBP risk and supportive factors such as social support or work control reduce the risk $[14,15]$. It is assumed that these psychosocial factors influence LBP development by inducing strain reactions $[19,28]$. Detachment in leisure time has been proven to buffer some negative effects of straining work situations, as well as support the recovery process and wellbeing [39]. However, these influences have been widely neglected in studies regarding LBP pathogenesis to date. The results of this study support the importance of considering recovery influences when investigating work-related LBP risk factors.

\section{LBP prevalence and intensity}

The sample under investigation reported a comparable prevalence of new LBP over the period of 6 months as in recent literature [7]. The reported values of the pain-related parameters indicate that the majority of the participants have had only minor complaints without serve disabilities, given that only 2 participants fell into the Grade 2 chronification category. Nevertheless, almost $3 / 4$ of those participants who had indicated LBP at 3-month follow-up also reported LBP at 6-month follow-up. This indicates that even though pain intensity was relatively low, several participants had long-lasting persistence or recurrent complaints over a 6-month period.

\section{Socio-demographic predictors}

The final GEE model revealed a strong influence of smoking behavior on LBP development, whereby those participants who did not smoke regularly showed a strongly reduced chance of LBP occurrence. These results are in line with recent literature [63-66]. In contrast to current research, age and gender had no significant influence on LBP development in this study. Several studies reported increasing age as prompting higher LBP risk [67,68] and an increased LBP risk for women [7,64,69]. Possible explanations for these missing effects might be found in the restricted range of age and small proportion of men in the study sample.

\section{Work-related predictors}

With respect to work stressors, no influence on LBP risk could be identified. These results are in contrast to recent reviews, which emphasize the importance of work stressors for the occurrence of LBP [14,15]. Similarly working hours and overtime per week had no influence on LBP risk. One possible explanation for the missing influence of work stressors might be found in the overall low scores and small standard variations for work stressors in the study sample.

The results regarding work-related LBP risk factors support the diminishing effect of work resources on LBP risk, as indicated in recent reviews $[14,15]$. Unfortunately, 3 subscales of the KFZA had to be merged together to avoid multicollinearity and thus no differentiated statements can be made about the separate influences of the work resources, work content or organizational factors. However, the odds ratio indicates a decreasing chance of LBP development when the overall work resources increase. This protective effect of work resources on back pain development is in line with the JD-R Model, which has recently been extended to health outcomes [70]. The specific effects for the separate types of work resources (for example, social support, control or versatility), however, should be investigated in future studies.

\section{Detachment}

In contrast to a previous cross-sectional study using the same data set [52], detachment only indirectly influenced the LBP risk. Accordingly, the first hypothesis has to be rejected. The identified interaction effect between detachment and work stressors supports the notion of detachment being a relevant moderating factor for LBP development. The results support the second hypothesis, namely that participants with high detachment 
values show no change in LBP probability when the work stressors increase. By contrast, those participants with low detachment values showed an increase in LBP probability when work stressors rose. Detachment seems to have a protective function and it is buffering the influence of work stressors on LBP.

Furthermore, the results emphasize the importance of detachment as a moderating factor for the influence of overall work resources on LBP risk. Based upon the previous empirical and theoretical results, it was assumed that employees with low work resources perceived higher strain and would benefit most from detachment processes. However, the interaction effect identified in the current study does not support these assumptions. The ability to detach after work had a stronger soothing effect on LBP development when work resources were high, whereas employees with low work resources benefited from a better detachment to a small degree only. Given that no differences between high and low detachment existed under low overall work resources, it seems like a good detachment in leisure time might not counteract the negative effect of low work resources but rather strengthen the positive influences of high work resources. Therefore, the third hypothesis could not be unrestrictedly accepted.

Job involvement and the associated work engagement might be relevant factors causing these effects [71]. Job involvement improves under good work conditions, as does work engagement, although a higher work engagement is also related to a decrease in detachment [72,73]. It is likely that employees in the investigated sample reacted to increasing work resources with higher work engagement and reduced detachment. Role salience - strongly related to job involvement - has also been shown to moderate the influence of detachment, with Sanz-Vergel et al. [74] showing that only employees with high home-role salience benefited from a good detachment. Further studies are necessary to clarify the interrelations of detachment and work resources in more detail.

\section{Limitations}

Alongside the already mentioned selectivity of the sample, another major limitation of this study is the high dropout rate resulting in a strong selection bias and a small sample size. This might have led to great confidence intervals and the absence of hypothesized results. However, no differences between the selected study sample and those participants who dropped out have been identified.

Another problem might be the use of the KFZA to examine the psychosocial work factors. This questionnaire has only been used in one cross-section study in relation to LBP and its discrimination power might be too low for this purpose. Furthermore, the questions of the KFZA are slightly different from other questionnaires used in previous studies; thus, the results might differ due to the form and content of the questionnaire used in this study. However, the KFZA has already been used in several German studies to specify work stressors and resources in employees of different professions [75-77]. The use of the KFZA was preferred over more commonly used English language questionnaires for this study due to its high practicability and efficiency in terms of time.

\section{CONCLUSIONS}

This study represents a first attempt to close the gap in knowledge regarding the influence of leisure time recovery on LBP. Despite the aforementioned limitations, the results of the present study provide support for the important role that detachment plays in the process of LBP development, as stated by Mierswa and Kellmann [28]. If these influences can be confirmed in future research, this would have a huge impact on LBP prevention.

To date, prevention concepts have been mostly concentrated on the work environment and the training of employees to reduce stress. However, if the recovery in leisure time could counteract the negative influences of highly straining work, employees should also be instructed how to recover efficiently in leisure time. Studies thus 
far have indicated that detachment plays a major role in this process [39]. As a result, future prevention programs should include modules to inform participants about the concept of detachment and teach them ways how to improve detachment.

In addition to the importance for prevention programs, the results of this study might also have implications for future investigations of psychosocial risk factors for LBP. The risk of LBP development is affected not only by work-related factors, but also by some psychological factors such as recovery experiences or social factors in leisure time $[16,78,79]$. Whereas several theoretical models stress the importance of recovery processes for health, only a few studies have investigated its influence on LBP. Furthermore, frequently used theoretical work-health models, e.g., the JD-R Model, neglect leisure-time recovery processes. Inclusion of recovery processes into these models might improve their applicability and validity.

Although the current study was based upon a small sample size, the findings clearly support the hypothesis of detachment moderating the influence of known psychosocial risk factors for LBP development. More longitudinal studies are necessary to further determine the influences of other recovery experiences on LBP and examine the validity of the findings in other samples. Furthermore, intervention studies aiming to increase the ability to detach after work could support the understanding of the role detachment plays in LBP development.

\section{REFERENCES}

1. Asche CV, Kirkness CS, McAdam-Marx C, Fritz JM. The societal costs of low back pain: Data published between 2001 and 2007. J Pain Palliat Care Pharmacother. 2007;21(4):2533, https://doi.org/10.1080/J354v21n04_06.

2. Buchbinder R, Blyth FM, March LM, Brooks P, Woolf AD, Hoy DG. Placing the global burden of low back pain in context. Best Pract Res Clin Rheumatol. 2013;27(5):575-89, https://doi.org/10.1016/j.berh.2013.10.007.
3. Dagenais S, Caro J, Haldeman S. A systematic review of low back pain cost of illness studies in the United States and internationally. Spine J. 2008;8(1):8-20, https://doi.org/ 10.1016/j.spinee.2007.10.005.

4. Froud R, Patterson S, Eldridge S, Seale C, Pincus T, Rajendran D, et al. A systematic review and meta-synthesis of the impact of low back pain on people's lives. BMC Musculoskelet Disord. 2014;15(1):50, https://doi.org/10.1186/14712474-15-50.

5. Mathew J, Singh SB, Garis S, Diwan AD. Backing up the stories: The psychological and social costs of chronic lowback pain. Int J Spine Surg. 2013;7:e29-38, https://doi.org/ 10.1016/j.ijsp.2013.02.001.

6. Strunin L, Boden LI. Family consequences of chronic back pain. Soc Sci Med. 2004;58(7):1385-93, https://doi.org/10. 1016/S0277-9536(03)00333-2.

7. Hoy D, Bain C, Williams G, March L, Brooks P, Blyth F, et al. A systematic review of the global prevalence of low back pain. Arthritis Rheum. 2012;64(6):2028-37, https://doi.org/ 10.1002/art.34347.

8. Thiese MS, Hegmann KT, Wood EM, Garg A, Moore JS, Kapellusch JM, et al. Low-back pain ratings for lifetime, 1-month period, and point prevalences in a large occupational population. Hum Factors. 2014;56(1):86-97, https:// doi.org/10.1177/0018720813493641.

9. Davis KK, Heaney CA. The relationship between psychosocial work characteristics and low back pain: Underlying methodological issues. Clin Biomech. 2000;15(6):389-406, https://doi.org/10.1016/S0268-0033(99)00101-1.

10. Eriksen HR, Ihlebæk C, Jansen JP, Burdorf A. The relations between psychosocial factors at work and health status among workers in home care organizations. Int J Behav Med. 2006;13(3):183-92.

11. Fernandes RCP, Carvalho FM, Assunção AA, Silvany Neto AM. Interactions between physical and psychosocial demands of work associated to low back pain. Rev Saude Publica. 2009;43(2):326-34, https://doi.org/10.1590/S0034-891020090 00200014. 
12. Leino PI, Hanninen V. Psychosocial factors at work in relation to back and limb disorders. Scand J Work Environ Health. 1995;21(2):134-42, https://doi.org/10.5271/sjweh.20.

13. Sterud T, Tynes T. Work-related psychosocial and mechanical risk factors for low back pain: A 3-year follow-up study of the general working population in Norway. Occup Environ Med. 2013;70:296-302, https://doi.org/10.1136/ oemed-2012-101116.

14. Hauke A, Flintrop J, Brun E, Rugulies R. The impact of work-related psychosocial stressors on the onset of musculoskeletal disorders in specific body regions: A review and meta-analysis of 54 longitudinal studies. Work Stress. 2011;25(3):243-56, https://doi.org/10.1080/02678373.2011. 614069 .

15. Lang J, Ochsmann E, Kraus T, Lang JW. Psychosocial work stressors as antecedents of musculoskeletal problems: A systematic review and meta-analysis of stability-adjusted longitudinal studies. Soc Sci Med. 2012;75(7):1163-74, https:// doi.org/10.1016/j.socscimed.2012.04.015.

16. Thorbjornsson CO, Alfredsson L, Fredriksson K, Koster M, Michelsen H, Vingard E, et al. Psychosocial and physical risk factors associated with low back pain: A 24 year follow up among women and men in a broad range of occupations. Occup Environ Med. 1998;55(2):84-90, https://doi.org/10.1136/ oem.55.2.84.

17. Yip YB, Ho SC. Effects of socio-psychological stress on new and recurrent low back pain among Chinese community middle-aged women. Psychol Health Med. 2001;6(4): 361-72, https://doi.org/10.1080/13548500126533.

18. Finestone H, Alfeeli A, Fisher W. Stress-induced physiologic changes as a basis for the biopsychosocial model of chronic musculoskeletal pain: A new theory? Clin J Pain. 2008;24(9):767-75, https://doi.org/10.1097/AJP.0b013e3181 790342 .

19. Marras WS. The working back: A systems view. Hoboken (NJ): John Wiley \& Sons, Inc.; 2008.

20. Marras WS. The complex spine: The multidimensional system of causal pathways for low-back disorders. Hum
Factors. 2012;54(6):881-9, https://doi.org/10.1177/00187208 12452129

21. Splittstoesser RE, Marras WS, Best TM. Immune responses to low back pain risk factors. Work. 2012;41(Suppl 1): 6016-23, https://doi.org/10.3233/WOR-2012-1053-6016.

22. Bakker AB, Demerouti E. The Job Demands-Resources model: State of the art. J Managerial Psychol. 2007;22(3): 309-28, https://doi.org/10.1108/02683940710733115.

23. Schaufeli WB, Taris TW. A critical review of the Job DemandsResources Model: Implications for improving work and health. In: Bauer GF, Hämmig O, editors. Bridging occupational, organizational and public health. Dordrecht: Springer; 2014. p. 43-68, https://doi.org/10.1007/978-94-007-5640-3_4.

24. McEwen BS. Stress, adaptation, and disease: Allostasis and allostatic load. Ann N Y Acad Sci. 1998;840(1):33-44.

25. Meijman TF, Mulder G. Psychological aspects of workload. In: Drenth PJD, Thierry H, de Wolff CJ, editors. Work psychology: Handbook of work and organizational psychology. 2nd ed. Hove: Psychology Press; 1998. p. 5-33.

26. Geurts SAE, Sonnentag S. Recovery as an explanatory mechanism in the relation between acute stress reactions and chronic health impairment. Scand J Work Environ Health. 2006;32(6):482-92, https://doi.org/10.5271/sjweh.1053.

27. Kallus KW. Introduction. In: Kallus KW, Kellmann M, editors. The Recovery-Stress Questionnaires: User manual. Frankfurt: Pearson Assessment \& Information GmbH; 2016.

28. Mierswa T, Kellmann M. The influences of recovery on low back pain development: A theoretical model. Int J Occup Med Environ Health. 2015;28(2):253-62, https://doi.org/ 10.13075/ijomeh.1896.00269.

29. Brosschot JF, Gerin W, Thayer JF. The perseverative cognition hypothesis: A review of worry, prolonged stress-related physiological activation, and health. J Psychosom Res. 2006;60(2): 113-24, https://doi.org/10.1016/j.jpsychores.2005.06.074.

30. Brosschot JF, Pieper S, Thayer JF. Expanding stress theory: Prolonged activation and perseverative cognition. Psychoneuroendocrinology. 2005;30(10):1043-9, https://doi.org/10. 1016/j.psyneuen.2005.04.008. 
31. Brosschot JF, van der Doef M. Daily worrying and somatic health complaints: Testing the effectiveness of a simple worry reduction intervention. Psychol Health. 2006;21(1):19-31, https://doi.org/10.1080/14768320500105346.

32. Fritz C, Yankelevich M, Zarubin A, Barger P. Happy, healthy, and productive: The role of detachment from work during nonwork time. J Appl Psychol. 2010;95(5):977-83, https://doi.org/10.1037/a0019462.

33. Siltaloppi M, Kinnunen U, Feldt T. Recovery experiences as moderators between psychosocial work characteristics and occupational well-being. Work Stress. 2009;23(4):33048, https://doi.org/10.1080/02678370903415572.

34. Ragsdale JM, Beehr TA, Grebner S, Han K. An integrated model of weekday stress and weekend recovery of students. Int J Stress Manag. 2011;18(2):153-80, https://doi. org/10.1037/a0023190.

35. Sonnentag S, Zijlstra FRH. Job characteristics and off-job activity as predictors of need for recovery, well-being, and fatigue. J Appl Psychol. 2006;91(2):330-50, https://doi.org/ 10.1037/0021-9010.91.2.330.

36. Sonnentag S, Binnewies C, Mojza EJ. "Did you have a nice evening?" A day-level study on recovery experiences, sleep, and affect. J Appl Psychol. 2008;93(3):674-84, https://doi. org/10.1037/0021-9010.93.3.674.

37. Sonnentag S, Kuttler I, Fritz C. Job stressors, emotional exhaustion, and need for recovery: A multi-source study on the benefits of psychological detachment. J Vocat Behav. 2010;76(3):355-65, https://doi.org/10.1016/j.jvb.2009. 06.005 .

38. Sonnentag S, Binnewies C, Mojza EJ. Staying well and engaged when demands are high: The role of psychological detachment. J Appl Psychol. 2010;95(5):965-76, https://doi. org/10.1037/a0020032.

39. Sonnentag S, Fritz C. Recovery from job stress: The stressordetachment model as an integrative framework. J Organ Behav. 2015;36(S1):S72-103, https://doi.org/10.1002/job.1924.

40. White E. Helping to promote psychological well-being at work: The role of work engagement, work stress and psy- chological detachment using the job demands-resources model. Plymouth Student Scientist. 2010;4(2):155-80.

41. Fritz C, Sonnentag S. Recovery, health, and job performance: Effects of weekend experiences. J Occup Health Psychol. 2005;10(3):187-99, https://doi.org/10.1037/10768998.10.3.187.

42. Fritz C, Sonnentag S. Recovery, well-being, and performance-related outcomes: The role of workload and vacation experiences. J Appl Psychol. 2006;91(4):936-45, https://doi. org/10.1037/0021-9010.91.4.936.

43. Sluiter JK, Frings-Dresen MH, van der Beek AJ, Meijman TF. The relation between work-induced neuroendocrine reactivity and recovery, subjective need for recovery, and health status. J Psychosom Res. 2001;50(1):29-37, https://doi.org/10.1016/S0022-3999(00)00213-0.

44. Sluiter JK, de Croon EM, Meijman TF, Frings-Dresen MH. Need for recovery from work related fatigue and its role in the development and prediction of subjective health complaints. Occup Environ Med. 2003;60(1):62-70, https://doi. org/10.1136/oem.60.suppl_1.i62.

45. Van der Starre RE, Coffeng JK, Hendriksen IJM, van Mechelen W, Boot CRL. Associations between overweight, obesity, health measures and need for recovery in office employees: A cross-sectional analysis. BMC Public Health. 2013;13:1207, https://doi.org/10.1186/1471-2458-13-1207.

46. Kivimaki M, Leino-Arjas P, Kaila-Kangas L, Luukkonen R, Vahtera J, Elovainio M, et al. Is incomplete recovery from work a risk marker of cardiovascular death? Prospective evidence from industrial employees. Psychosom Med. 2006;68(3):402-7, https://doi.org/10.1097/01.psy.0000 221285.50314.d3.

47. Van Amelsvoort LG, Kant IJ, Bultmann U, Swaen GMH. Need for recovery after work and the subsequent risk of cardiovascular disease in a working population. Occup Environ Med. 2003;60 Suppl 1:i83-7, https://doi.org/10.1136/oem.60. suppl_1.i83.

48. De Jonge J, Spoor E, Sonnentag S, Dormann C, van den Tooren M. "Take a break?!” Off-job recovery, job demands, 
and job resources as predictors of health, active learning, and creativity. Eur J Work Organ Psychol. 2012;21(3): 321-48, https://doi.org/10.1080/1359432X.2011.576009.

49. Gawke JC, Gorgievski MJ, van der Linden D. Office work and complaints of the arms, neck and shoulders: The role of job characteristics, muscular tension and need for recovery. J Occup Health. 2012;54(4):323-30, https://doi.org/10.1539/ joh.11-0152-OA.

50. Machin MA, Hoare PN. The role of workload and driver coping styles in predicting bus drivers' need for recovery, positive and negative affect, and physical symptoms. Anxiety Stress Coping. 2008;21(4):359-75, https://doi.org/ 10.1080/10615800701766049.

51. De Croon EM, Sluiter JK, Frings-Dresen MH. Need for recovery after work predicts sickness absence: A 2-year prospective cohort study in truck drivers. J Psychosom Res. 2003;55(4):331-9, https://doi.org/10.1016/S0022-3999 (02)00630-X.

52. Mierswa T, Kellmann M. [Psychosocial working conditions and back pain: The moderating effect of detachment in leisure time]. Z Gesundh Psychol. 2014;22(3):129-49, https:// doi.org/10.1026/0943-8149/a000121. German.

53. Dickinson CE, Campion K, Foster AF, Newman SJ, O'Rourke AM, Thomas PG. Questionnaire development: An examination of the Nordic Musculoskeletal questionnaire. Appl Ergon. 1992;23(3):197-201, https://doi.org/ 10.1016/0003-6870(92)90225-K.

54. Byström P, Hanse JJ, Kjellberg A. Appraised psychological workload, musculoskeletal symptoms, and the mediating effect of fatigue: A structural equation modeling approach. Scand J Psychol. 2004;45(4):331-41, https://doi.org/10.1111/ j.1467-9450.2004.00413.x.

55. Eatough EM, Way JD, Chang C-H. Understanding the link between psychosocial work stressors and work-related musculoskeletal complaints. Appl Ergon. 2012;43(3):554-63, https://doi.org/10.1016/j.apergo.2011.08.009.

56. Lin R-T, Chan C-C. Effectiveness of workstation design on reducing musculoskeletal risk factors and symptoms among semiconductor fabrication room workers. Int J Ind Ergon. 2007;37(1):35-42, https://doi.org/10.1016/j.ergon.2006. 09.015 .

57. Klasen BW, Hallner D, Schaub C, Willburger R, Hasenbring M. Validation and reliability of the German version of the Chronic Pain Grade questionnaire in primary care back pain patients. Psychosoc Med. 2004;1:1-12.

58. Von Korff M, Ormel J, Keefe FJ, Dworkin SF. Grading the severity of chronic pain. Pain. 1992;50(2):133-49.

59. Prümper J, Hartmannsgruber K, Frese M. [KFZA. ShortQuestionnaire for work analysis]. Z Arb Organ. 1995;39: 125-32. German.

60. Sonnentag S, Fritz C. The Recovery Experience Questionnaire: Development and validation of a measure for assessing recuperation and unwinding from work. J Occup Health Psychol. 2007;12(3):204-21, https://doi.org/10.1037/1076-89 98.12.3.204.

61. Ballinger GA. Using generalized estimating equations for longitudinal data analysis. Organ Res Methods. 2004;7(2): 127-50, https://doi.org/10.1177/1094428104263672.

62. Pan W. Akaike's information criterion in generalized estimating equations. Biometrics. 2001;57(1):120-5.

63. Goldberg MS, Scott SC, Mayo NE. A review of the association between cigarette smoking and the development of nonspecific back pain and related outcomes. Spine. 2000;25(8): 995-1014, https://doi.org/10.1097/00007632-200004150-00016.

64. Karahan A, Kav S, Abbasoglu A, Dogan N. Low back pain: Prevalence and associated risk factors among hospital staff. J Adv Nurs. 2009;65(3):516-24, https://doi.org/10.1111/j.13 65-2648.2008.04905.x.

65. Mikkonen P, Leino-Arjas P, Remes J, Zitting P, Taimela S, Karppinen J. Is smoking a risk factor for low back pain in adolescents? A prospective cohort study. Spine. 2008;33(5): 527-32, https://doi.org/10.1097/BRS.0b013e3181657d3c.

66. Shiri R, Karppinen J, Leino-Arjas P, Solovieva S, ViikariJuntura E. The association between smoking and low back pain: A meta-analysis. Am J Med. 2010;123(1):87.e7-35, https://doi.org/10.1016/j.amjmed.2009.05.028. 
67. Kopec JA, Sayre EC, Esdaile JM. Predictors of back pain in a general population cohort. Spine. 2004;29(1):70-8, https:// doi.org/10.1097/01.BRS.0000103942.81227.7F.

68. Dionne CE, Dunn KM, Croft PR. Does back pain prevalence really decrease with increasing age? A systematic review. Age Ageing. 2006;35(3):229-34, https://doi.org/10.1093/ageing/afj055.

69. Schneider S, Schmitt H, Zoller S, Schiltenwolf M. Workplace stress, lifestyle and social factors as correlates of back pain: A representative study of the German working population. Int Arch Occup Environ Health. 2005;78(4):253-69, https://doi.org/10.1007/s00420-004-0576-4.

70. Brauchli R, Jenny GJ, Füllemann D, Bauer GF. Towards a Job Demands-Resources Health Model: Empirical testing with generalizable indicators of job demands, job resources, and comprehensive health outcomes. Biomed Res Int. 2015;2015:959621, https://doi.org/10.1155/2015/959621.

71. Sonnentag S, Mojza EJ, Binnewies C, Scholl A. Being engaged at work and detached at home: A week-level study on work engagement, psychological detachment, and affect. Work Stress. 2008;22(3):257-76, https://doi.org/10.1080/02 678370802379440.

72. Kühnel J, Sonnentag S, Westman M. Does work engagement increase after a short respite? The role of job involvement as a double-edged sword. J Occup Organ Psychol. 2009;82(3): 575-94, https://doi.org/10.1348/096317908X349362.
73. Sonnentag S, Kruel U. Psychological detachment from work during off-job time: The role of job stressors, job involvement, and recovery-related self-efficacy. Eur J Work Organ Psychol. 2006;15:197-217, https://doi.org/10.1080/13594320500513939.

74. Sanz-Vergel AI, Demerouti E, Bakker AB, Moreno-Jimenez B. Daily detachment from work and home: The moderating effect of role salience. Hum Relation. 2011;64(6):775-99, https://doi.org/10.1177/0018726710393368.

75. Neubach B, Schmidt K-H. [Differential correlations of work demands and resources with burnout]. Z Arb Organ. 2004;48: 25-30, https://doi.org/10.1026/0932-4089.48.1.25. German.

76. Treier M. [Moments of stress and strain in home-based telework]. Z Arb Organ. 2003;47:24-35, https://doi.org/10.1026// 0932-4089.47.1.24. German.

77. Wegge J, Neuhaus L. [Emotions during office work at the PC: A test of the affective events theory]. Z Arb Organ. 2002;46:173-84, https://doi.org/10.1026//0932-4089.46.4.173. German.

78. Yip YB. The association between psychosocial work factors and future low back pain among nurses in Hong Kong: A prospective study. Psychol Health Med. 2002;7(2):223-33, https://doi.org/10.1080/13548500120116157.

79. Yip YB, Ho SC, Chan SG. Identifying risk factors for low back pain (LBP) in Chinese middle-aged women: A casecontrol study. Health Care Women Int. 2004;25(4):358-69, https://doi.org/10.1080/07399330490278367.

This work is available in Open Access model and licensed under a Creative Commons Attribution-NonCommercial 3.0 Poland License - http://creativecommons.org/ licenses/by-nc/3.0/pl/deed.en. 